\title{
The Performance and Mechanism Analysis of Cement Pastes Added to Aluminum Sulfate-Based Low-Alkali Setting Accelerator
}

\author{
Xingdong Lv, ${ }^{1,2}$ Yan Shi, ${ }^{1}$ Yun Dong, ${ }^{1}$ Zhiyang Gao, ${ }^{1}$ and Beixing $\mathrm{Li}^{2}$ \\ ${ }^{1}$ Changjiang River Scientific Research Institute of Changjiang Water Resources Commission, Wuhan 430010, China \\ ${ }^{2}$ State Key Laboratory of Silicate Materials for Architecture, Wuhan University of Technology, Wuhan 430070, China \\ Correspondence should be addressed to Xingdong Lv; 1115650343@qq.com
}

Received 30 June 2016; Revised 17 October 2016; Accepted 24 October 2016; Published 31 January 2017

Academic Editor: Sverak Tomas

Copyright ( $\odot 2017$ Xingdong Lv et al. This is an open access article distributed under the Creative Commons Attribution License, which permits unrestricted use, distribution, and reproduction in any medium, provided the original work is properly cited.

We proposed a type of low-alkali liquid state setting accelerator, named HLSA; it was environmentally friendly product. To investigate the temperature adaptation and cement flexibilities of HLSA, the setting time and strength development properties of cement with HLSA were discussed in this paper. The effects of HLSA on hydration process, hydration products, and microstructure were studied by means of X-ray diffraction (XRD), thermogravimetric analysis (TGA), scanning electron microscope (SEM), and mercury intrusion porosimetry (MIP). The results show that four typical 42.5-grade ordinary Portland cement types with 6-8\% HLSA could satisfy the first-grade requirements according to JC477-2005 even at a lower temperature (e.g., $\left.10^{\circ} \mathrm{C}\right)$. Further, the percentage ratio of $28 \mathrm{~d}$ compressive strength of cement with 6-8\% HLSA was over $90 \%$; the XRD diffraction peak of AFt integrated area of cement with 7\% HLSA was 3818 at 5 min of hydration; SEM observation revealed that AFt crystals were filled in the pore of cement at $28 \mathrm{~d}$ of hydration; the temperature adaptation and cement flexibilities of HLSA were excellent; the cement with HLSA coagulating in a short time attributed to promoting the formation of abundant AFt and the hydration of $\mathrm{C}_{3} \mathrm{~S}$.

\section{Introduction}

Shotcrete is a kind of concrete which is conveyed under pressure through a pneumatic hose or pipe and projected into place at high velocity, with simultaneous compaction, condensation, and hardening $[1,2]$. The shotcrete can acquire high early age strength and coagulate in a short time [3]; it is often used for hydraulic engineering, slope engineering, emergency rescue, and repairing engineering $[4,5]$. The setting accelerator is an essential component of shotcrete. The development of setting accelerator was dated back to the nineteen-thirties; the setting accelerators were mainly powder accelerators at the early stage of development. The powder accelerators easily lead to problems of dust pollution, dispersing unevenly and high energy consumption in construction process. Meanwhile, it is harmful to construction crews' health at some degrees in dry spray of construction process. With the developing of wet sprayed technology of shotcrete, liquid setting accelerators emerged in nineteen-eighties [6].
The liquid setting accelerators can avoid the problems of dust pollution and uneven dispersing caused by powder accelerators in dry spray process. The main chemical components of traditional setting accelerators are classified as (1) sodium silicates-based, such as water glass and modified sodium silicate; (2) aluminate-based, such as sodium aluminate, potassium aluminate, and aluminum sulfate; (3) carbonate and hydroxide-based, such as sodium carbonate and sodium hydroxide [7]. The common problems that existed was that the alkali content of the liquid and powder setting accelerators were very high at the early research stage of setting accelerators. The high alkali setting accelerators could easily lead to the following problems: (1) increasing the risk of alkali-aggregate reaction in concrete; (2) being harmful to the builders' health with extremely high $\mathrm{pH}$ level; (3) a severe reduction of the shotcrete long-term mechanical properties [8]. According to EN 934-5 [9], the low-alkali setting accelerators are defined as setting accelerators whose alkali metal content (sodium and potassium), expressed as 
TABLE 1: Chemical composition of cement (w/\%).

\begin{tabular}{lcccccccc}
\hline Cement & $\mathrm{SiO}_{2}$ & $\mathrm{CaO}$ & $\mathrm{Al}_{2} \mathrm{O}_{3}$ & $\mathrm{Fe}_{2} \mathrm{O}_{3}$ & $\mathrm{MgO}$ & $\mathrm{SO}_{3}$ & $\mathrm{R}_{2} \mathrm{O}$ & Loss \\
\hline $\mathrm{H}$ & 23.49 & 58.24 & 6.00 & 2.81 & 2.35 & 2.39 & 0.76 & 3.06 \\
$\mathrm{Y}$ & 21.02 & 62.38 & 4.80 & 3.68 & 1.03 & 2.02 & 0.60 & 3.78 \\
\hline
\end{tabular}

TABLE 2: Main chemical composition of HLSA (w/\%).

\begin{tabular}{lccccc}
\hline Sample & $\mathrm{Al}_{2} \mathrm{O}_{3}$ & $\mathrm{SO}_{3}$ & $\mathrm{Na}_{2} \mathrm{O}$ & $\mathrm{F}^{-}$ & Loss \\
\hline HLSA & 8.43 & 19.82 & 5.04 & 3.21 & 60.15 \\
\hline
\end{tabular}

equivalent of $\mathrm{Na}_{2} \mathrm{O} \%+0.658 \mathrm{~K}_{2} \mathrm{O} \%$, is not above $8 \%$ by mass. The low-alkali setting accelerators have some significant advantages. Therefore, the preparation of low-alkali setting accelerators has been the main trend and hot topic in this field [10].

The setting accelerators consist of many types and the acceleration mechanism is not conclusive; the present theories of acceleration mechanism are as follows: (1) the formation of abundant AFt in a short time of the setting accelerators based on aluminate. A large amount of $\mathrm{SO}_{4}{ }^{2-}$ from setting accelerator can react with aluminate hydration products of cement to form AFt and high reactive secondary gypsum. The AFt crystals are connecting reticular structure in cement pastes; the formation of cement hydration products especially calcium aluminate hydrate needs to combine free water leading to cement condensation in a short time [11] and (2) the formation of abundant hydrated calcium aluminate of the setting accelerators based on carbonate and sodium silicates. Due to the obvious decrease of gypsum concentration, the retard effect of gypsum is weakened and even vanished, which promotes the hydration of $\mathrm{C}_{3} \mathrm{~A}$ to form cubic crystal $\mathrm{C}_{3} \mathrm{AH}_{6}$ in a short time. Then massive heat is released at the same time and the cement paste is setting rapidly [12].

However, the effects of different setting accelerators addition on cement were also different; meanwhile, the variation of hydration products mass percentage of cement containing setting accelerators was rarely studied. As a result, the aluminum sulfate-based low-alkali liquid state setting accelerator named HLSA has been prepared in laboratory. HLSA was environmentally friendly product; it could avoid damaging the crews' health and decrease the energy consumption in construction process. The properties of setting time and strength development of cement in addition to HLSA were investigated. The effects of HLSA on hydration process, hydration products, and microstructure were investigated by means of X-ray diffraction (XRD), thermogravimetric analysis (TGA), scanning electron microscope (SEM), and mercury intrusion porosimetry (MIP).

\section{Experimental}

2.1. Raw Materials. The cement used was two typical 42.5grade ordinary Portland cement types, which were manufactured by Yadong (Y) Cement Company Ltd. (Wuhan, Hubei) and Huaxin $(\mathrm{H})$ Cement Company Ltd. (Wuhan, Hubei), respectively. The Portland cement blended with less than $20 \%$ mineral admixtures. The physical and chemical properties of Portland cement all satisfied China National Standard GB 175-2007; the chemical composition of cement was shown in Table 1.

The HLSA prepared in lab were synthesized by industrialgrade aluminum sulfate $\left(\mathrm{Al}_{2}\left(\mathrm{SO}_{4}\right)_{3} \cdot 18 \mathrm{H}_{2} \mathrm{O}\right)$, chemically pure sodium fluoride $(\mathrm{NaF})$, chemically pure triethanolamine $\left(\left(\mathrm{HOCH}_{2} \mathrm{CH}_{2}\right)_{3} \mathrm{~N}\right)$, chemically pure polyacrylamide $\left(-\left[\mathrm{CH}_{2} \mathrm{CH}\right]_{n} \mathrm{CONH}_{2}-\right)$, and chemically pure phosphoric acid $\left(\mathrm{H}_{3} \mathrm{PO}_{4}\right)$. The industrial-grade aluminum sulfate was obtained from the Zibo Guangzheng Aluminum Salt Chemical Industry Co., Ltd. (Zibo, Shandong). The chemically pure sodium fluoride, triethanolamine, polyacrylamide, and phosphoric acid were obtained from Sinopharm.

HLSA was light green homogeneous liquid in appearance with density of $1.61 \mathrm{~g} / \mathrm{cm}^{3}$ and solid content of $40.5 \%$. The alkali content expressed as equivalent of $\mathrm{Na}_{2} \mathrm{O} \%+0.658$ $\times \mathrm{K}_{2} \mathrm{O} \%$ was $5.0 \%$, which belongs to low-alkali setting accelerator. The main chemical composition of HLSA was shown in Table 2.

\subsection{Experimental Methods}

2.2.1. Cement Setting Time. The setting time of cement with HLSA was measured according to Chinese Building Materials Standards JC 477-2005 with water to cement ratio (W/C) 0.40 ; the dosage of setting accelerator was $6 \%, 7 \%$, and $8 \%$ (by mass of cement) respectively. The cement pastes were cured under the condition of temperature $20 \pm 2^{\circ} \mathrm{C}$ and RH not less than $90 \%$. The effect of HLSA on cement setting time at $10^{\circ} \mathrm{C}$ and $20^{\circ} \mathrm{C}$ was investigated, respectively, it used Yangdong P.O 42.5 Portland cement and Huaxin P.O 42.5 Portland cement, and the composition mix was shown in Table 3.

2.2.2. Strength Development of Cement Mortar. The measurement of cement mortar strength development was according to Chinese Building Materials Standards JC 477-2005. With standard sand:cement: water ratio of $3: 2: 1$, the addition of setting accelerator was $6 \%, 7 \%$, and $8 \%$ (by mass of cement), respectively. Cement mortar specimens were $40 \mathrm{~mm}$ $\times 40 \mathrm{~mm} \times 160 \mathrm{~mm}$ prisms. The specimens were prepared and cured in molds for $24 \mathrm{~h}$ under the condition of temperature $20 \pm 2^{\circ} \mathrm{C}$ and $\mathrm{RH}$ over $90 \%$; then they were demoulded and tested for $1 \mathrm{~d}$ compressive strength immediately; the 
TABLE 3: Mix proportions of cement paste.

\begin{tabular}{|c|c|c|c|c|}
\hline Types & $\mathrm{W} / \mathrm{C}$ & Cement type & Temperature $/{ }^{\circ} \mathrm{C}$ & Dosage/\% \\
\hline Y10-S6 & 0.4 & \multirow{6}{*}{ Yangfang P.O 42.5} & \multirow{3}{*}{10} & 6 \\
\hline Y10-S7 & 0.4 & & & 7 \\
\hline Y10-S8 & 0.4 & & & 8 \\
\hline Y20-S6 & 0.4 & & \multirow{3}{*}{20} & 6 \\
\hline Y20-S7 & 0.4 & & & 7 \\
\hline Y20-S8 & 0.4 & & & 8 \\
\hline H10-S6 & 0.4 & \multirow{6}{*}{ Huaxin P.O 42.5} & \multirow{3}{*}{10} & 6 \\
\hline H10-S7 & 0.4 & & & 7 \\
\hline H10-S8 & 0.4 & & & 8 \\
\hline H20-S6 & 0.4 & & \multirow{3}{*}{20} & 6 \\
\hline H20-S7 & 0.4 & & & 7 \\
\hline $\mathrm{H} 20-\mathrm{S} 8$ & 0.4 & & & 8 \\
\hline
\end{tabular}

percentage of mortar in addition to HLSA compressive strength growth at $1 \mathrm{~d}$ was characterized by the following:

$$
C_{1}(\%)=100 \times \frac{C_{(a 1)}-C_{(b 1)}}{C_{(b 1)}}(\%),
$$

where $C_{1}(\%)$ was growth rate of compressive strength at $1 \mathrm{~d}, C_{(a 1)}$ were compressive strength of specimens containing HLSA at $1 \mathrm{~d}$, and $C_{(b 1)}$ were compressive strength of blank specimens at $1 \mathrm{~d}$.

The rest of specimens were cured under the condition of air temperature $20 \pm 2^{\circ} \mathrm{C}$ and $\mathrm{RH}$ not less than $90 \%$. The retention percentage of compressive strength at $28 \mathrm{~d}$ was characterized by the following:

$$
C_{28}(\%)=100 \times \frac{C_{(H 28)}}{C_{(B 28)}}(\%),
$$

where $C_{28}(\%)$ was retention percentage of compressive strength at $28 \mathrm{~d}, \mathrm{C}_{(\mathrm{H} 28)}$ were compressive strength of specimens containing HLSA at $28 \mathrm{~d}$, and $C_{(B 28)}$ were compressive strength of blank specimens at $28 \mathrm{~d}$.

2.2.3. Microstructure of Hardened Cement Pastes. Cement pastes were prepared for X-ray diffraction (XRD), thermogravimetric analysis (TGA), scanning electron microscope (SEM), and mercury intrusion porosimetry (MIP) analyses on water to cement ratio 0.40 in addition to $7 \%$ HLSA. The hydration of hardened cement pastes was stopped after predetermined curing age by breaking test block into small pieces in absolute ethyl alcohol. The small samples were ground into powders with particle size less than $80 \mu \mathrm{m}$ by agate grinding for XRD and TGA analyses. The small samples with particle size range from $5 \mathrm{~mm}$ to $8 \mathrm{~mm}$ were selected for SEM analyses. Fresh paste was cast into capsules $(3 \mathrm{~mm}$ diameter, $45 \mathrm{~mm}$ height) cured under water and stored at $20^{\circ} \mathrm{C}$. At required time of hydration, a slice $(2 \mathrm{~mm}$ thick $)$ of hardened paste was cut for MIP analyses.

XRD was employed to identify the cement hydration phase. The XRD data were collected by Bruker D8 advance diffractometer with a $3 \mathrm{KW} \mathrm{Cu} \mathrm{K} \alpha$ radiation and the X-ray tube was operated at $40 \mathrm{kV}$ and $40 \mathrm{~mA}$. The scanning speed of XRD was $10^{\circ} / \mathrm{min}$. The software MDI Jade 6.5 was used to study the special diffraction peak of ettringite and $\mathrm{CH}$ for quantitative phase analyses [13]. TG analysis was used to test the weight loss and decomposition temperature of phase. All samples were tested within the range of $25^{\circ} \mathrm{C}$ to $800^{\circ} \mathrm{C}$ using a differential thermal analyzer (STA449C from Netzsch, Germany) under air atmosphere with a scanning rate of $15^{\circ} \mathrm{C} / \mathrm{min}$. The field emission electron microscopy (Ultra Plus-43-13 from Zeiss, Germany) was used to observe morphology and microstructure of cement pastes. MIP measurement was carried out on micromeritics instrument corporation AutoPore IV 9500 mercury scanning porosimeter, with maximum pressure $228 \mathrm{MPa}$, and its measurable pore size ranges from $3 \mathrm{~nm}$ to $1000 \mathrm{um}$.

In order to investigate the amount of cement hydration products in addition to HLSA. Method of semiquantitative analysis was used to study the diffraction peak characteristics of hydration products $\mathrm{AFt}$ and $\mathrm{Ca}(\mathrm{OH})_{2}(\mathrm{CH})$ by software Jade 6. DTG curves clearly showed the relationship between temperature and weight loss in case the weight loss was close. The decomposition peak of $\mathrm{CH}$ occurred between 420 and $460^{\circ} \mathrm{C}$ in DTG curves; the amount of $\mathrm{CH}$ could be calculated by the following formula:

$$
\mathrm{CH}(\%)=\mathrm{WL}_{\mathrm{CH}}(\%) \frac{\mathrm{MW}_{\mathrm{CH}}}{\mathrm{MW}_{\mathrm{H}_{2} \mathrm{O}}},
$$

where $\mathrm{WL}_{\mathrm{CH}}(\%)$ corresponds to the weight loss of $\mathrm{CH}$ in percent and $\mathrm{MW}_{\mathrm{CH}}$ and $\mathrm{MW}_{\mathrm{H}_{2} \mathrm{O}}$ were the molecular weights of portlandite and water, respectively [14].

\section{Results and Discussion}

3.1. Temperature Adaptation. Temperature was an important external factor affecting chemical reaction rate. The temperature of concrete raw materials was changeable when the regions, seasons, and daily temperature changed, so it should pay attention to the problems caused by the changeable temperature in construction process [15]. In order to investigate the effect of HLSA on cement setting time at 


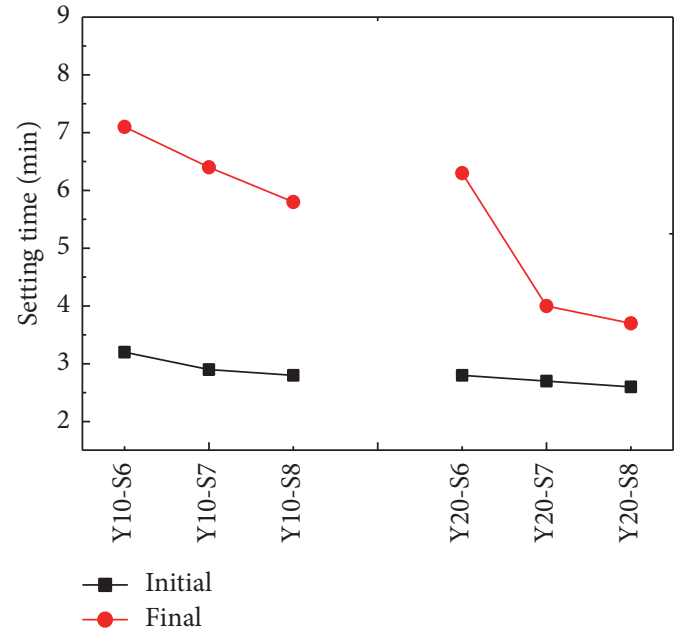

(a) $\mathrm{Y}$

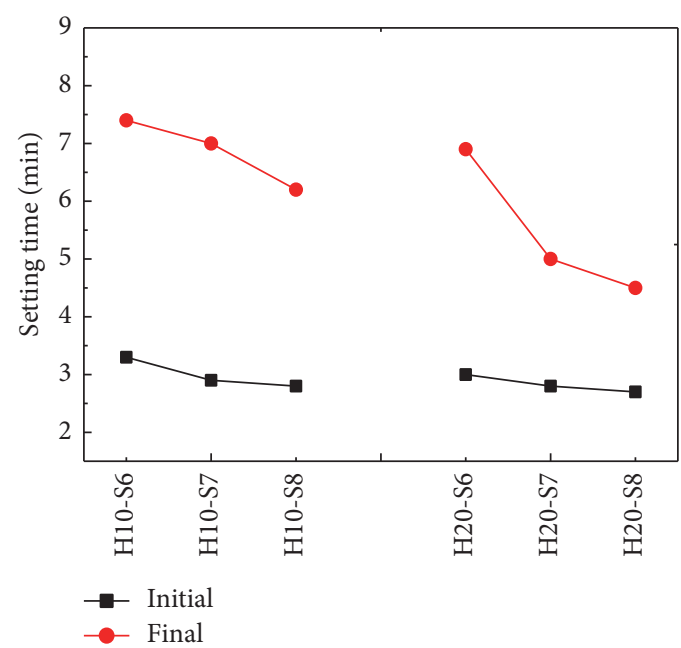

(b) $\mathrm{H}$

Figure 1: Effect of setting time of cement in addition to HLSA at $10^{\circ} \mathrm{C}$ and $20^{\circ} \mathrm{C}$.

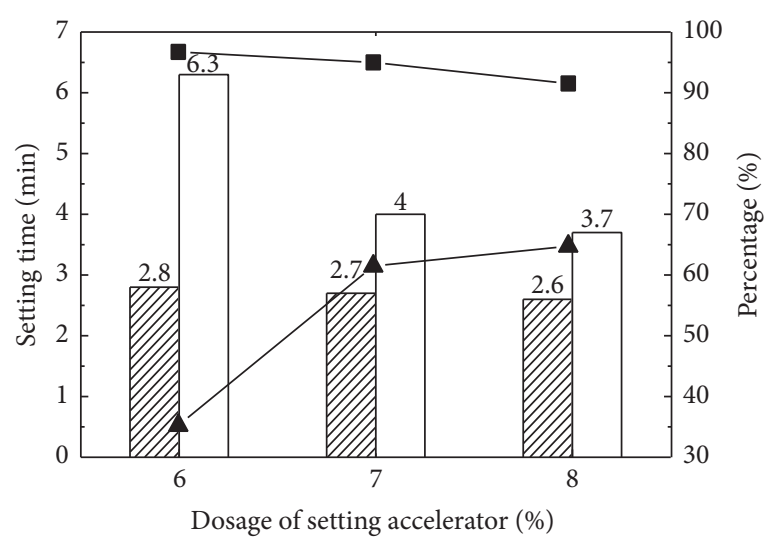

$\begin{array}{ll}\square & \text { Initial } \\ \square \text { Final } & C_{1} \\ \square & C_{28}\end{array}$

(a) $\mathrm{Y}$

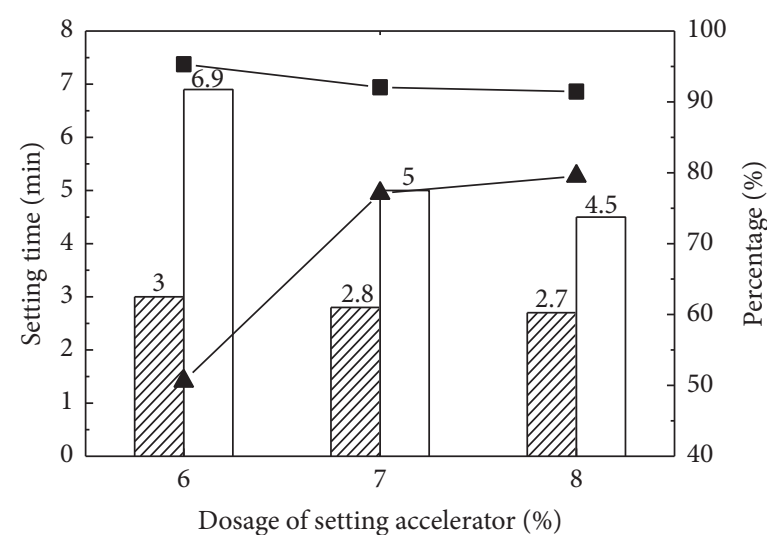

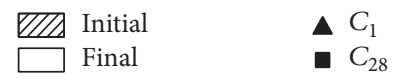

(b) $\mathrm{H}$

FIGURE 2: Effect of setting time and strength development of two kinds of cement containing HLSA.

different environment temperature, the tunnel temperature of summer and winter was simulated in lab. The effect of setting time of cement in addition to HLSA at $10^{\circ} \mathrm{C}$ and $20^{\circ} \mathrm{C}$ was investigated; the results were shown in Figure 1.

The cement setting time was shortened as the curing temperature was higher at the same dosage. The setting time of cement in addition to 6\% HLSA could meet first-grade requirement according to Chinese Building Materials Standards JC $477-2005$ at temperature $20^{\circ} \mathrm{C}$. The setting time of cement in addition to $6 \%$ HLSA could meet acceptable product requirement according to JC 477-2005 at temperature $10^{\circ} \mathrm{C}$. It could be supposed that the temperature adaptation of HLSA was excellent, as it could maintain the flash setting effect at lower temperature (e.g., $10^{\circ} \mathrm{C}$ ). The setting time could meet the first-grade requirement by increasing the dosage of setting accelerator at lower temperature.
3.2. Cement Flexibilities. The cement setting time and cement mortar strength development in addition to $6 \%, 7 \%$, and $8 \%$ HLSA were investigated; the results were shown in Figure 2. It was supposed that the adaptation between admixture and cement was good as the concrete or mortars prepared with the admixture could generate desired performance; on the contrary, it could be thought that the adaptation between admixture and cement was not good according to Chinese Standard GB 50119-2013 [16].

The setting time of cement in addition to HLSA at the dosage range from $6 \%$ to $8 \%$ could meet the firstgrade requirement according to Chinese Building Materials Standards JC 477-2005, especially cement Y and cement H which could meet first-grade requirement at the dosage $6 \%$. The higher the dosage was, the shorter the setting time would be. The compressive strength growth of mortars prepared 


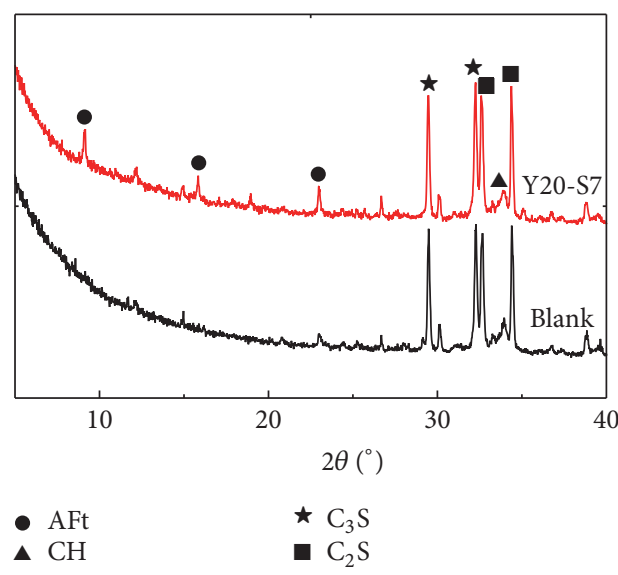

(a) $5 \mathrm{~min}$

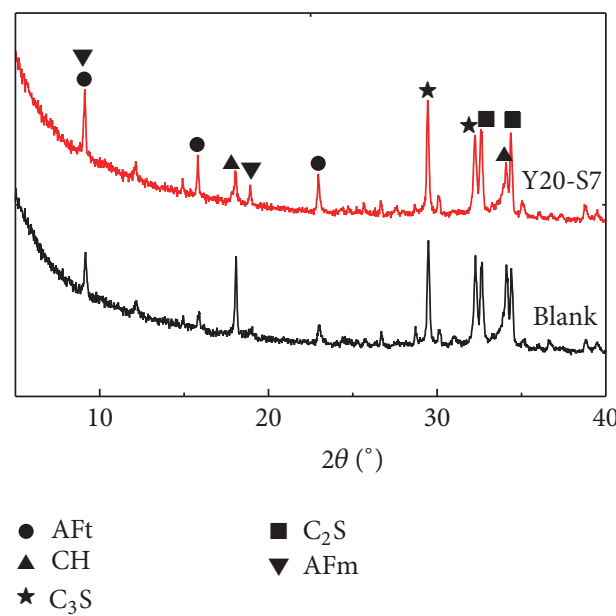

(c) $1 \mathrm{~d}$

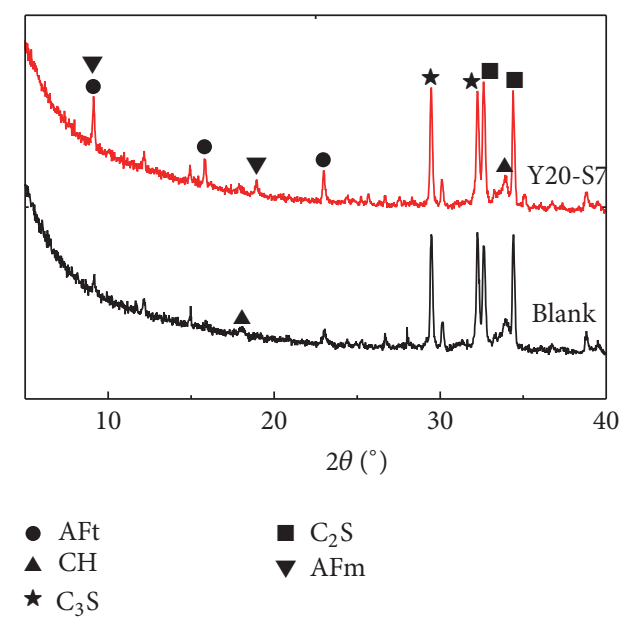

(b) $5 \mathrm{~h}$

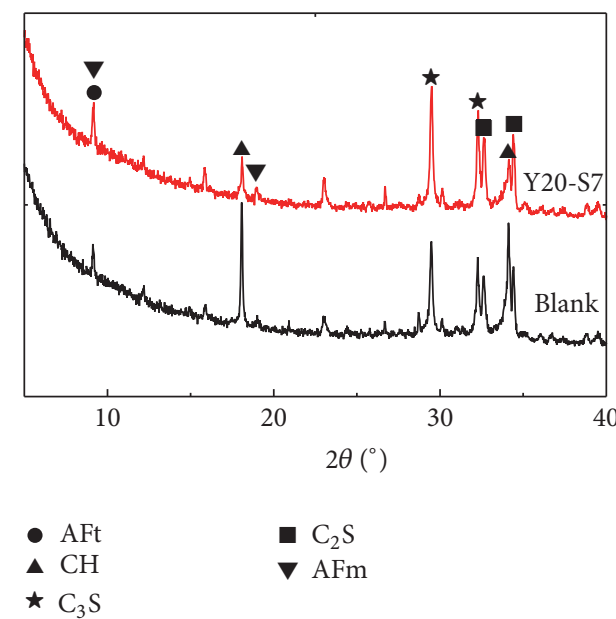

(d) $28 \mathrm{~d}$

FIGURE 3: XRD patterns of hydrated cement in addition to 7\% HLSA.

with two cement types at $1 \mathrm{~d}$ presented an increasing trend as the dosage increased. Compressive strength growths of mortars prepared with two cement types at $1 \mathrm{~d}$ were all above $40 \%$ at the dosage of $8 \%$; it was noted that compressive strength growth of mortar prepared with cement $\mathrm{Y}$ and cement $\mathrm{H}$ at $1 \mathrm{~d}$ was all above $60 \%$. The $28 \mathrm{~d}$ retention percentage of mortar compressive strength was all above $90 \%$, which was much higher than the first-grade requirement of $75 \%$ according to JC 477-2005. It is suggested that HLSA could avoid the problems of significant strength loss at late stage caused by high alkali content of traditional setting accelerators. Consequently, the cement flexibilities of HLSA were excellent.

3.3. XRD Analysis. Figure 3 showed XRD patterns of hydrated cement with 7\% HLSA (Y20-S7) and blank specimens at the age of $5 \mathrm{~min}, 5 \mathrm{~h}, 1 \mathrm{~d}$, and $28 \mathrm{~d}$, respectively. The integrated results of XRD diffraction peak of AFt corresponding to $2 \theta$ range of $9.0-10.0^{\circ}$ and $\mathrm{CH}$ corresponding to $2 \theta$ range of $17.0-19.0^{\circ}$ were shown in Tables 4 and 5 , respectively.
The Y20-S7 specimen presented intensive diffraction peak of AFt while the blank specimens never detected diffraction peak of AFt after $5 \mathrm{~min}$ of hydration; it suggested that Y20-S7 specimen had generated AFt at 5 min of hydration. The Y20-S7 specimen diffraction peak integrated area of AFt was $252.0 \%$ of the blank specimens at $5 \mathrm{~h}$ of hydration. The Y20-S7 specimen diffraction peak integrated area of AFt at $5 \mathrm{~h}$ of hydration presented decreasing trend compared to $5 \mathrm{~min}$ of hydration. The XRD curve of Y20-S7 specimen detected a weak diffraction peak of AFm at $5 \mathrm{~h}$ of hydration; it was possible that the AFt partially converted into AFm due to the concentration of $\mathrm{SO}_{4}{ }^{2-}$ in pore solution of cement decreasing sharply [17]; the chemical reaction occurred:

$$
\mathrm{AFt}+2 \mathrm{C}_{4} \mathrm{AH}_{13} \longrightarrow 3 \mathrm{AFm}+2 \mathrm{CH}+20 \mathrm{H}
$$

(see $[18,19])$.

The blank specimen diffraction peak integrated area of AFt at $1 \mathrm{~d}$ of hydration was approximate to the Y20-S7 specimen at $5 \mathrm{~min}$ of hydration. It suggested that the amount of AFt of Y20-S7 specimen generated during 5 min was approximate to the ordinary Portland cement hydration 
TABLE 4: The integrated results of XRD diffraction peak of AFt corresponding to $2 \theta$ range of $9.0-10.0^{\circ}$.

\begin{tabular}{|c|c|c|c|c|c|}
\hline Specimens & Hydration age & $d$-value $(\AA)$ & FWHM $\left(^{\circ}\right)$ & Height & Area \\
\hline \multirow{4}{*}{ Blank } & $5 \mathrm{~min}$ & - & - & - & - \\
\hline & $5 \mathrm{~h}$ & 9.6494 & 0.175 & 124 & 1312 \\
\hline & $1 \mathrm{~d}$ & 9.6666 & 0.175 & 343 & 3626 \\
\hline & $28 \mathrm{~d}$ & 9.6680 & 0.132 & 218 & 1745 \\
\hline \multirow{4}{*}{ Y20-S7 } & $5 \mathrm{~min}$ & 9.6888 & 0.203 & 311 & 3818 \\
\hline & $5 \mathrm{~h}$ & 9.6884 & 0.150 & 365 & 3306 \\
\hline & $1 \mathrm{~d}$ & 9.6909 & 0.108 & 497 & 3240 \\
\hline & $28 \mathrm{~d}$ & 9.6798 & 0.167 & 300 & 3035 \\
\hline
\end{tabular}

TABLE 5: The integrated results of XRD diffraction peak of $\mathrm{CH}$ corresponding at $2 \theta$ range of $17.0-19.0^{\circ}$.

\begin{tabular}{|c|c|c|c|c|c|}
\hline Specimens & Hydration age & $d$-value $(\AA)$ & FWHM $\left(^{\circ}\right)$ & Height & Area \\
\hline \multirow{2}{*}{ Blank } & $1 \mathrm{~d}$ & 4.9080 & 0.154 & 442 & 4124 \\
\hline & $28 \mathrm{~d}$ & 4.9033 & 0.149 & 914 & 8269 \\
\hline \multirow{2}{*}{ Y20-S7 } & $1 \mathrm{~d}$ & 4.9135 & 0.177 & 196 & 2098 \\
\hline & $28 \mathrm{~d}$ & 4.8978 & 0.189 & 277 & 3172 \\
\hline
\end{tabular}

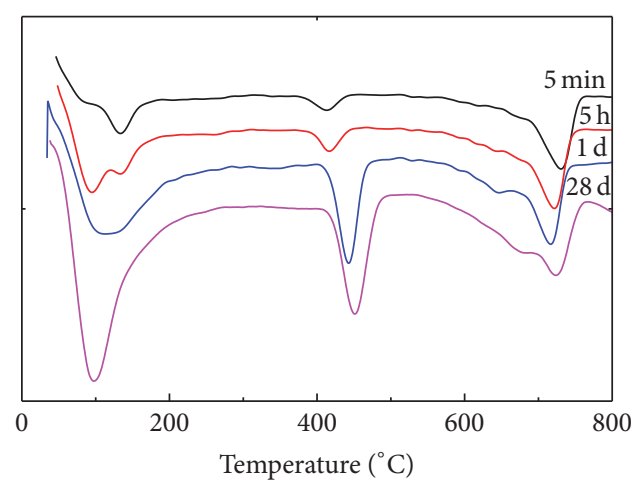

(a) Blank

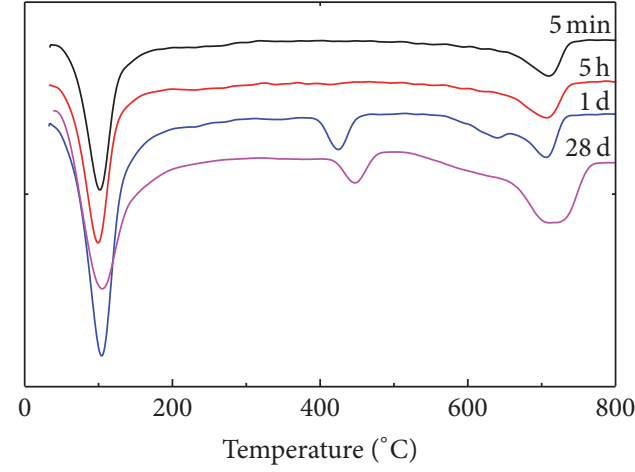

(b) Y20-S7

FIGURE 4: DTG curves of hydrated cement.

during $1 \mathrm{~d}$. The Y20-S7 specimen diffraction peak integrated area of $\mathrm{CH}$ at $1 \mathrm{~d}$ and $28 \mathrm{~d}$ was $50.8 \%$ and $38.4 \%$ of blank specimen, respectively, and the Y20-S7 specimen diffraction peak integrated area of $\mathrm{CH}$ was less than the blank specimen from $1 \mathrm{~d}$ to $28 \mathrm{~d}$ of hydration.

3.4. DTG Analysis. The effect of HLSA on cement hydration products was investigated by the means of differential scanning calorimetry analysis; the results were shown in Figure 4.

The weight loss peaks between 0 and $200^{\circ} \mathrm{C}$ of DTG curves were complicated. It was generally acknowledged that $\mathrm{AFt}, \mathrm{C}-\mathrm{S}-\mathrm{H}$, and gypsum decomposition occurred in this temperature range. However, the decomposition peaks of C$\mathrm{S}-\mathrm{H}$ and AFt were overlapped [20]. Li et al. [21] suggested that the weight loss at $20-80^{\circ} \mathrm{C}$ is caused by the decomposition of AFt; according to Chang et al. [22] the transformation of $\mathrm{CaSO}_{4} \cdot 2 \mathrm{H}_{2} \mathrm{O}$ to $\mathrm{CaSO}_{4} \cdot 0.5 \mathrm{H}_{2} \mathrm{O}$ in temperature ranges from 80 to $140^{\circ} \mathrm{C}$. As Odler et al. [19, 23] suggested it was possible to assign the first two peaks at 120 and $145^{\circ} \mathrm{C}$ to ettringite and gypsum decomposition. The DTG curve of blank specimen occurred at intensive decomposition peak of $\mathrm{AFt}$ at $5 \mathrm{~h}$ of hydration; it is suggested that AFt had already been generated at that moment. The decomposition peak corresponding to AFt of Y20-S7 specimen presented increase at first and then decrease from $1 \mathrm{~d}$ to $28 \mathrm{~d}$ of hydration; it indicated that $\mathrm{AFt}$ was transformed to AFm at some degrees; the results were consistent with XRD analysis of Section 3.3. The CH content in hydrated cement pastes was demonstrated in Figure 5. It suggested $\mathrm{CH}$ content of Y20-S7 specimen was less than the blank specimen from $1 \mathrm{~d}$ to $28 \mathrm{~d}$ of hydration again; $\mathrm{CH}$ content of Y20-S7 specimen at $1 \mathrm{~d}$ and $28 \mathrm{~d}$ was $44.0 \%$ and $39.9 \%$ of the blank specimen, respectively.

3.5. SEM Analysis. Figure 6 showed scanning electron microscope (SEM) photographs of hydrated cement specimens containing 7\% HLSA. A large amount of AFt and C-S-H of Y20-S7 specimen was formed at $5 \mathrm{~min}$ of hydration; the needle-like AFt connected with each other compactly to 
TABLE 6: Parameters and distribution of pore of cement pastes at $1 \mathrm{~d}$ and $28 \mathrm{~d}$.

\begin{tabular}{|c|c|c|c|c|c|c|c|}
\hline \multirow{2}{*}{ Specimens } & \multirow{2}{*}{ Curing age/d } & \multirow{2}{*}{ Total pore volume $/\left(\mathrm{mL} \cdot \mathrm{g}^{-1}\right)$} & \multirow{2}{*}{ Porosity/\% } & \multicolumn{4}{|c|}{ Pore size distribution $/\left(\mathrm{mL} \cdot \mathrm{g}^{-1} / \%\right)$} \\
\hline & & & & $3-20 \mathrm{~nm}$ & $20-50 \mathrm{~nm}$ & $50-100 \mathrm{~nm}$ & $>100 \mathrm{~nm}$ \\
\hline Blank & 1 & 0.258 & 39.5 & $0.051 / 19.8$ & $0.051 / 19.8$ & $0.106 / 41.1$ & $0.050 / 19.3$ \\
\hline Y20-S7 & 1 & 0.235 & 35.2 & $0.062 / 26.4$ & $0.038 / 16.2$ & $0.095 / 40.4$ & $0.040 / 17.0$ \\
\hline Blank & 28 & 0.189 & 29.7 & $0.034 / 18.0$ & $0.070 / 37.0$ & $0.041 / 21.7$ & $0.044 / 23.3$ \\
\hline Y20-S7 & 28 & 0.161 & 27.1 & $0.023 / 14.3$ & $0.073 / 45.3$ & $0.028 / 17.4$ & $0.037 / 23.0$ \\
\hline
\end{tabular}

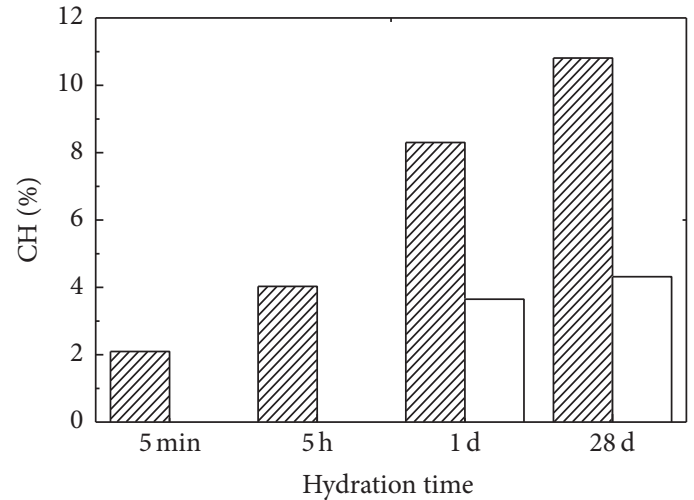

VIIA Blank Y20-S7

Figure 5: $\mathrm{CH}$ content in hydrated cement pastes.

form reticular structure. It was observed that some hexagonal shape portlandite crystals and a little of AFt crystals of blank specimen were formed at $5 \mathrm{~h}$ of hydration. Some AFt crystals of Y20-S7 specimen were still observed at $5 \mathrm{~h}$ of hydration; however, the amount of AFt was decreasing compared to $5 \mathrm{~min}$ of hydration; meanwhile the hexagonal shape portlandite crystals were unobserved. The amorphous $\mathrm{C}-\mathrm{S}-\mathrm{H}$ and AFt crystals were distributed in the cement and a few portlandite crystals were formed of Y20-S7 specimen at $1 \mathrm{~d}$ of hydration. The apparent morphology of blank specimen was dense and amorphous C-S-H and portlandite crystals grew compactly. However, needle-like AFt and amorphous C-S-H of Y20-S7 specimens grew crisscrossed compactly and AFt crystals were filled in the pore of cement.

3.6. Pore Structure Analysis. The cumulative pore volume of hardened cement paste was considered a main factor to cement pastes mechanical properties. It was believed that strength development of cement paste increased by the decrease of cumulative pore volume. The differential distribution curve was calculated from the cumulative pore volume curve [24]; according to Wu and Lian [25], the pores of hardened cement pastes were classified as harmless pore $(<20 \mathrm{~nm})$, little harmful pore $(20-50 \mathrm{~nm})$, and harmful pore $(50-200 \mathrm{~nm})$. The pore structures of hardened cement were measured by means of MIP; the results were shown in Table 6. The total porosity of Y20-S7 specimen was less than the blank specimen at $1 \mathrm{~d}$ and $28 \mathrm{~d}$ of hydration. The pores with pore diameter between 3 and $20 \mathrm{~nm}$ of Y20-S7 specimen were $6.6 \%$ more than the blank specimen at $1 \mathrm{~d}$ of hydration. It indicated that HLSA could reduce hardened cement paste pore size at early age of hydration. Meanwhile, it was beneficial to improve the cement mechanical properties at early age. The pores with pore diameter less than $50 \mathrm{~nm}$ of Y20-S7 specimen were $4.6 \%$ more than the blank specimen at $28 \mathrm{~d}$ of hydration; it showed that HLSA could refine pore structures at some degrees; it is induced to improve retention percentage of compressive strength at late age.

3.7. Acceleration Mechanism of HLSA. The effect of HLSA on cement hydration products amount was characterized that a large amount of crystallization of AFt was formed at very early age of hydration; the amount of AFt crystals were slightly decreasing at $5 \mathrm{~h}$ of hydration; however the content of AFt was still very high at $28 \mathrm{~d}$ of hydration. The content of $\mathrm{CH}$ crystals was lower than the blank specimen from $1 \mathrm{~d}$ to $28 \mathrm{~d}$ of hydration.

The main components of HLSA were $\mathrm{SO}_{4}{ }^{2-}, \mathrm{Al}^{3+}$, and $\mathrm{F}^{-}$. When HLSA and cement contacted, the following reaction would be taking place:

$$
\begin{aligned}
& \mathrm{Ca}^{2+}+\mathrm{F}^{-} \longrightarrow \mathrm{CaF}_{2} \downarrow \\
& 2 \mathrm{Al}^{3+}+3 \mathrm{SO}_{4}{ }^{2-}+3 \mathrm{CH}+6 \mathrm{H}_{2} \mathrm{O} \\
& \quad \longrightarrow 3 \mathrm{CS}_{2}+2 \mathrm{Al}(\mathrm{OH})_{3} \\
& \mathrm{C}_{3} \mathrm{~A}+3 \mathrm{C} \overline{\mathrm{S}} \mathrm{H}_{2}+26 \mathrm{H} \\
& \quad \longrightarrow 3 \mathrm{CaO} \cdot \mathrm{Al}_{2} \mathrm{O}_{3} \cdot 3 \mathrm{CaSO}_{4} \cdot 32 \mathrm{H}_{2} \mathrm{O}(\mathrm{AFt}) \\
& 6 \mathrm{CH}+\mathrm{Al}_{2}\left(\mathrm{SO}_{4}\right)_{3}+26 \mathrm{H} \\
& \longrightarrow 3 \mathrm{CaO}_{3} \mathrm{Al}_{2} \mathrm{O}_{3} \cdot 3 \mathrm{CaSO}_{4} \cdot 32 \mathrm{H}_{2} \mathrm{O}(\mathrm{AFt}) \\
& \mathrm{Al}(\mathrm{OH})_{3}+3 \mathrm{CH}+3 \mathrm{CS} \mathrm{H}_{2}+24 \mathrm{H} \\
& \longrightarrow 3 \mathrm{CaO} \cdot \mathrm{Al}_{2} \mathrm{O}_{3} \cdot 3 \mathrm{CaSO}_{4} \cdot 32 \mathrm{H}_{2} \mathrm{O}(\mathrm{AFt})
\end{aligned}
$$

$\mathrm{CaF}_{2}$ was formed readily because it was more easily crystallized than $\mathrm{CH}$. The balance of electric double layer of $\mathrm{C}_{3} \mathrm{~S}$ surface was destructed because abundant $\mathrm{Ca}^{2+}$ was consumed, which led to the formation of the electric double layer of $\mathrm{C}_{3} \mathrm{~S}$ difficultly and shortened the induction period of $\mathrm{C}_{3} \mathrm{~S}$ greatly [26]. The Y20-S7 specimen had generated C-S-H gel at 5 min of hydration; it suggested that $\mathrm{C}_{3} \mathrm{~S}$ had begun to hydrate at that moment.

Equation (6) showed that the free state of $\mathrm{Al}^{3+}$ and $\mathrm{SO}_{4}{ }^{2-}$ readily combined $\mathrm{CH}$ in cement to form highly reactive 

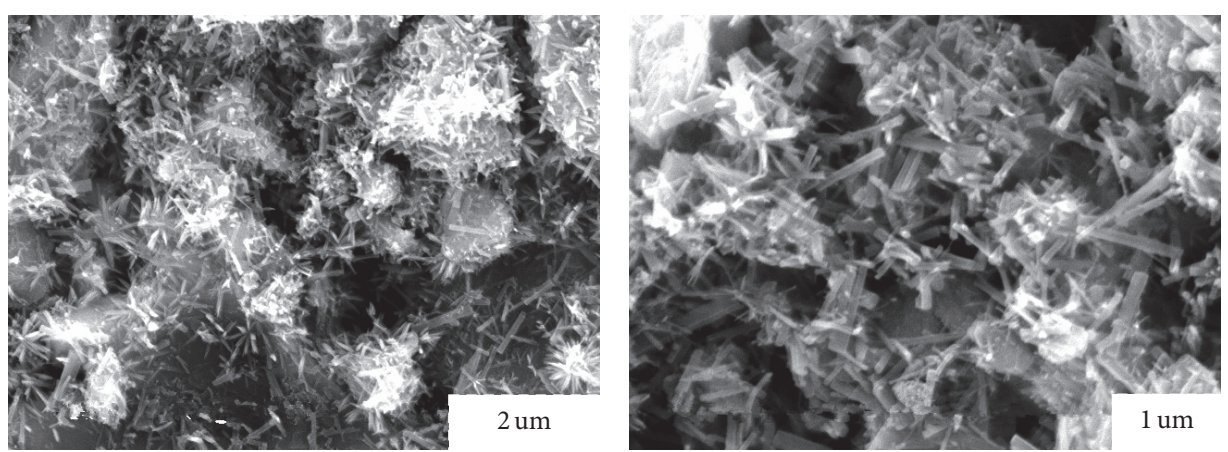

(a) Y20-S7 $5 \mathrm{~min}$

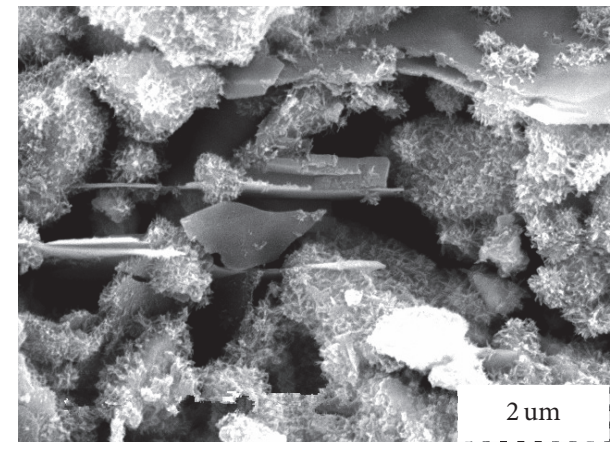

(b) Blank $5 \mathrm{~h}$

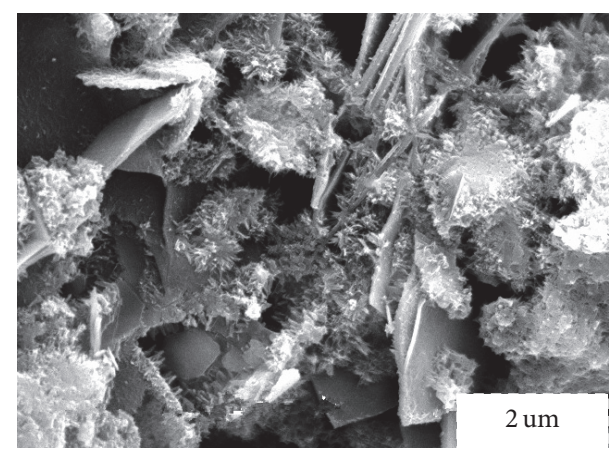

(d) Blank 1d

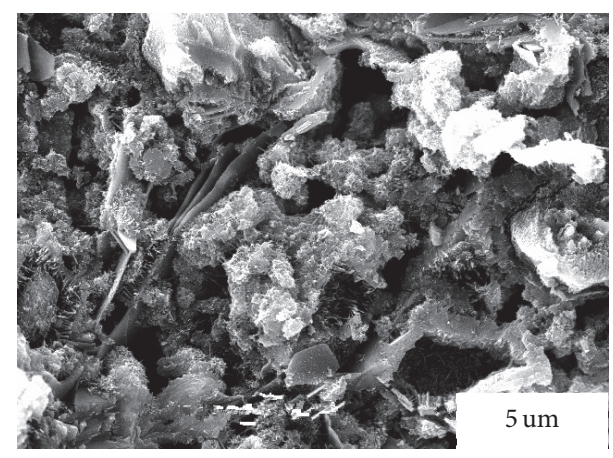

(f) Blank 28d

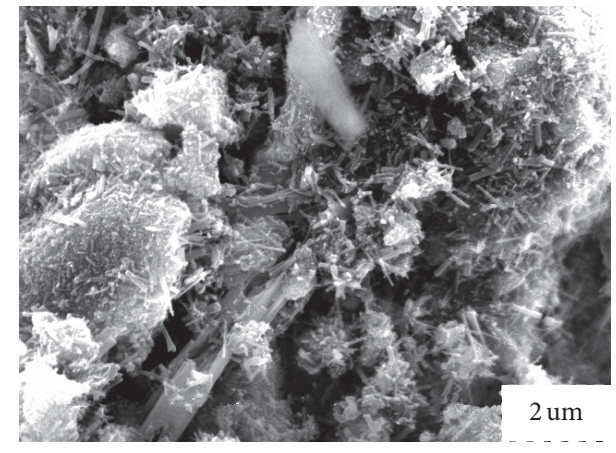

(c) Y20-S7 $5 \mathrm{~h}$

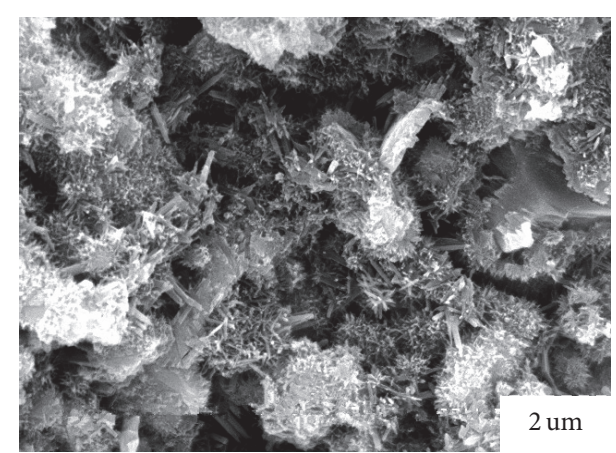

(e) Y20-S7 1d

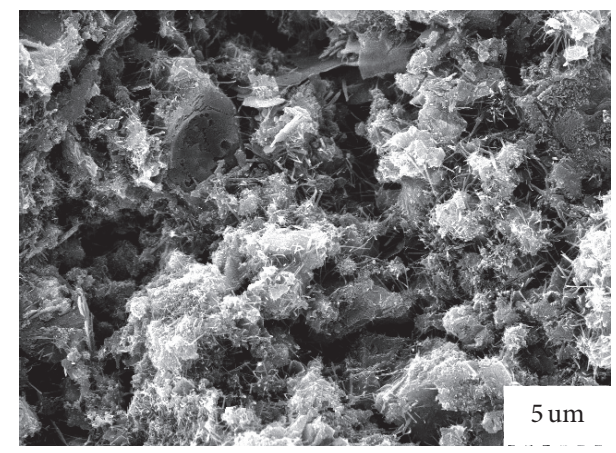

(g) Y20-S7 $28 \mathrm{~d}$

FIGURE 6: Scanning electron microscope (SEM) photographs of hydrated cement specimens. 
secondary gypsum and secondary gypsum easily reacted with the hydration products of $\mathrm{C}_{3} \mathrm{~A}$ to form AFt. Equation (8) suggested that aluminum sulfate reacted with $\mathrm{CH}$ to form $\mathrm{AFt}$ in aqueous alkaline medium at normal temperature. The approaches of the formation of AFt were extensive; it led to the formation of a large amount of AFt in a short time. The cement with HLSA coagulating in a short time attributed to a large of amount AFt connected reticular structure and distributed uniformly in cement pastes. Meanwhile, the HLSA shortened induction period of $\mathrm{C}_{3} \mathrm{~S}$ and promoted the hydration of $\mathrm{C}_{3} \mathrm{~S}$ greatly.

\section{Conclusions}

(1) The temperature adaptation and cement flexibilities of HLSA were excellent. The cement setting time could meet the first-grade requirements according to JC 477-2005 when increasing the dosage of $1 \%$ at temperature $10^{\circ} \mathrm{C}$ compared to temperature $20^{\circ} \mathrm{C}$. The setting time of cement with HLSA at the dosage range from $6 \%$ to $8 \%$ could meet the first-grade requirements according to JC 477-2005; meanwhile the cement retention percentage of compressive strength at $28 \mathrm{~d}$ was all above $90 \%$.

(2) The Y20-S7 specimen XRD diffraction peak of AFt integrated area was 3818; however the blank specimen was 0 at $5 \mathrm{~min}$ of hydration. The Y20-S7 specimen diffraction peak of AFt integrated area was 252.0\% of the blank specimen at $5 \mathrm{~h}$ of hydration. The $\mathrm{CH}$ amount of Y20-S7 specimen was less than the blank specimen from $1 \mathrm{~d}$ to $28 \mathrm{~d}$ of hydration. HLSA could reduce hardened cement paste pores size at early age of hydration and refine the pores structures at some degrees.

(3) The acceleration mechanism of HLSA attributed to promote the hydration of $\mathrm{C}_{3} \mathrm{~A}$ and the formation of AFt in a short time. Meanwhile, HLSA could shorten the induction period of $\mathrm{C}_{3} \mathrm{~S}$ greatly and promote the hydration of $\mathrm{C}_{3} \mathrm{~S}$.

\section{Competing Interests}

The authors declare that there is no conflict of interests regarding the publication of this paper.

\section{Acknowledgments}

The work described in this paper was supported by the National Natural Science Foundation of China under Grant nos. 51479011 and 51139001.

\section{References}

[1] J. Wang, D. Niu, S. Ding, Z. Mi, and D. Luo, "Microstructure, permeability and mechanical properties of accelerated shotcrete at different curing age," Construction and Building Materials, vol. 78, pp. 203-216, 2015.
[2] J.-P. Won, U.-J. Hwang, C.-K. Kim, and S.-J. Lee, "Mechanical performance of shotcrete made with a high-strength cementbased mineral accelerator," Construction and Building Materials, vol. 49, pp. 175-183, 2013.

[3] J. Wang, D. Niu, and Y. Zhang, "Mechanical properties, permeability and durability of accelerated shotcrete," Construction and Building Materials, vol. 95, pp. 312-328, 2015.

[4] C. Maltese, C. Pistolesi, A. Bravo, F. Cella, T. Cerulli, and D. Salvioni, "A case history: effect of moisture on the setting behaviour of a Portland cement reacting with an alkali-free accelerator," Cement and Concrete Research, vol. 37, no. 6, pp. 856-865, 2007.

[5] C. K. Y. Leung, R. Lai, and A. Y. F. Lee, "Properties of wetmixed fiber reinforced shotcrete and fiber reinforced concrete with similar composition," Cement and Concrete Research, vol. 35, no. 4, pp. 788-795, 2005.

[6] C. Snyder Raymond and F. Snyder Paul, Liquid concrete acelerator mixtures and methods for use thereof USA, 4046584, September 1997.

[7] S. A. Austin and P. J. Robins, Sprayed Concrete Properties, Design and Application, McGraw-Hill, London, UK, 1995.

[8] L. R. Prudêncio Jr., "Accelerating admixtures for shotcrete," Cement and Concrete Composites, vol. 20, no. 2-3, pp. 213-219, 1998.

[9] EN 934-5, Admixture for Sprayed Concrete-Definitions, Requirements, Conformity, Marking and Labelling, Standards Policy and Strategy Committee, 2007.

[10] Z. Pan, X. Wang, and W. Liu, "Properties and acceleration mechanism of cement mortar added with low alkaline liquid state setting accelerator," Journal Wuhan University of Technology, Materials Science Edition, vol. 29, no. 6, pp. 1196-1200, 2014.

[11] X. Xin and D. Qingjun, "Summary of cement rapid-setting adition and their mechanism researches," Journal of Wuhan University of Technology, vol. 21, no. 1, pp. 28-30, 1999.

[12] L. Chen, L. Shizong, W. Yanrong, and Y. Bilan, "Study on the accelerating mechanism of accelerators in concrete," Journal of Building Materials, vol. 3, no. 2, pp. 175-181, 2000.

[13] R. Wang, X.-G. Li, and P.-M. Wang, "Influence of polymer on cement hydration in SBR-modified cement pastes," Cement and Concrete Research, vol. 36, no. 9, pp. 1744-1751, 2006.

[14] A. Peschard, A. Govin, P. Grosseau, B. Guilhot, and R. Guyonnet, "Effect of polysaccharides on the hydration of cement paste at early ages," Cement and Concrete Research, vol. 34, no. 11, pp. 2153-2158, 2004.

[15] C. Paglia, F. Wombacher, and H. Böhni, “The influence of alkalifree and alkaline shotcrete accelerators within cement systems: influence of the temperature on the sulfate attack mechanisms and damage," Cement and Concrete Research, vol. 33, no. 3, pp. 387-395, 2003.

[16] S. Zhenping, J. Zhengwu, and W. Peiming, "Measures to improve compatibility between concrete admixtures and cement," Journal of Building Materials, vol. 6, no. 4, pp. 404-409, 2003.

[17] D. Niu, J. Wang, and Y. Wang, "Effect of hydration aging and water binder ratio on microstructure and mechanical properties of sprayed concrete," Journal Wuhan University of Technology, Materials Science Edition, vol. 30, no. 4, pp. 745-751, 2015.

[18] Y. Runzhang, Cementitious Materials Science, Wuhan University of Technology Press, Wuhan, China, 2006.

[19] I. Odler and S. Abdul-Maula, "Possibilities of quantitative determination of the AFt-(ettringite) and AFm-(monosulphate) 
phases in hydrated cement pastes," Cement and Concrete Research, vol. 14, no. 1, pp. 133-141, 1984.

[20] W. Prince, M. Espagne, and P.-C. Aitcin, "Ettringite formation: a crucial step in cement superplasticizer compatibility," Cement and Concrete Research, vol. 33, no. 5, pp. 635-641, 2003.

[21] G. Li, T. He, D. Hu, and C. Shi, "Effects of two retarders on the fluidity of pastes plasticized with aminosulfonic acid-based superplasticizers," Construction and Building Materials, vol. 26, no. 1, pp. 72-78, 2012.

[22] H. Chang, P. J. Huang, and S. C. Hou, "Application of thermoRaman spectroscopy to study dehydration of CaSO $4 \cdot 2 \mathrm{H} 2 \mathrm{O}$ and CaSO4.0.5H2O," Materials Chemistry and Physics, vol. 58, no. 1, pp. 12-19, 1999.

[23] J. Bensted and S. P. Varma, "Some applications of infrared and Raman spectroscopy in cement chemistry Part 3. Hydration of portland cement and its constituents," Cement Technology, vol. 5, no. 5, pp. 5440-5450, 1974.

[24] E. Berodier and K. Scrivener, "Evolution of pore structure in blended systems," Cement and Concrete Research, vol. 73, pp. 25-35, 2015.

[25] Z. Wu and H. Lian, High Performance Concrete, Railway Publishing House, Beijing, China, 1999.

[26] J. Wang, J. Song, K. Liu, and D. Wang, "Study on the low alkali liquid flash setting admixture of aluminum sulfate for shotcrete," Concrete, vol. 302, no. 12, pp. 84-87, 2014. 

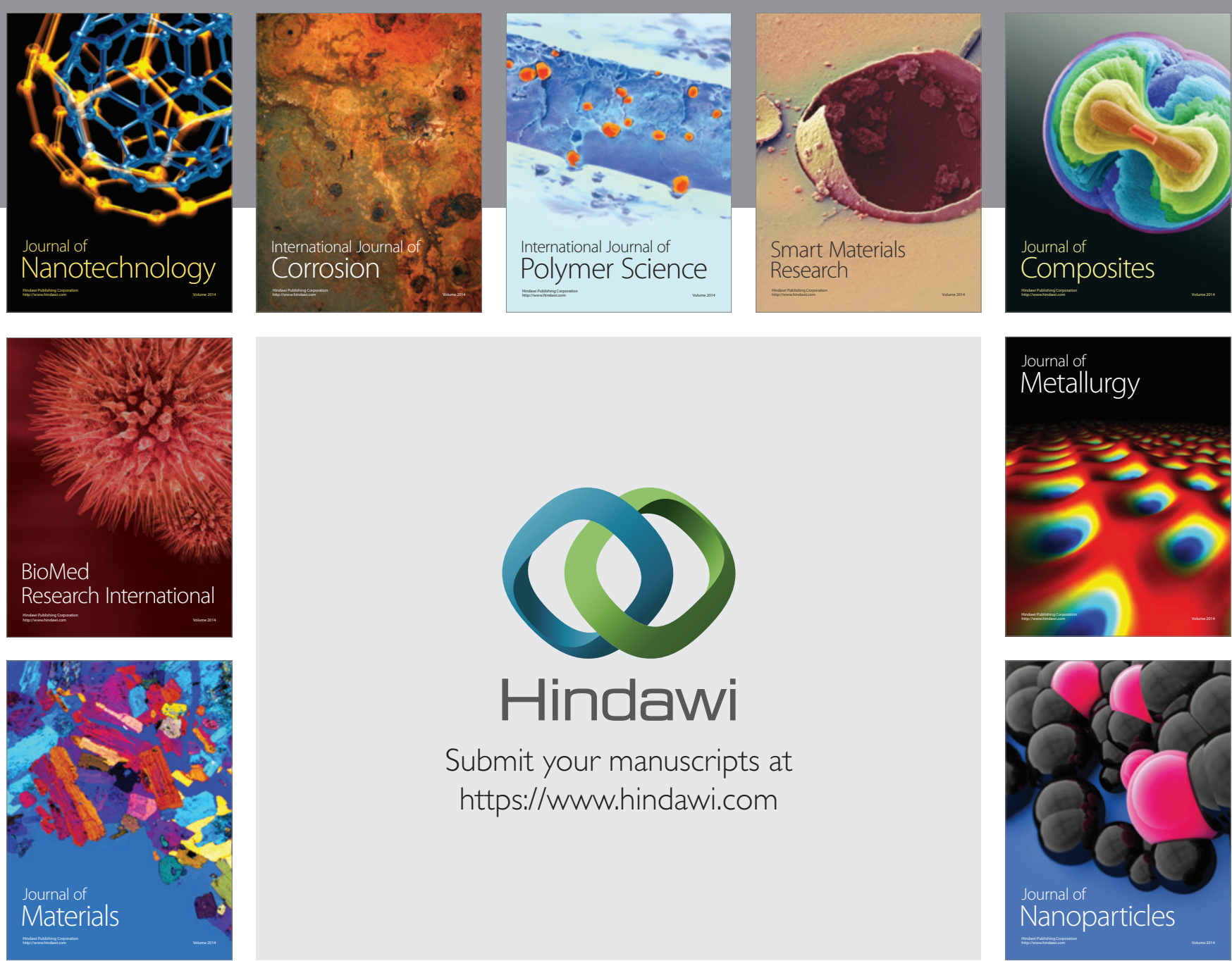

\section{Hindawi}

Submit your manuscripts at

https://www.hindawi.com

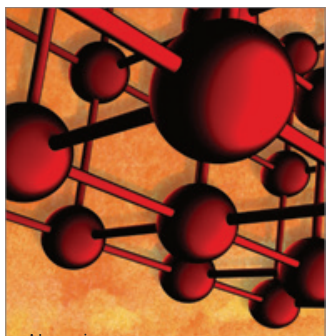

Materials Science and Engineering
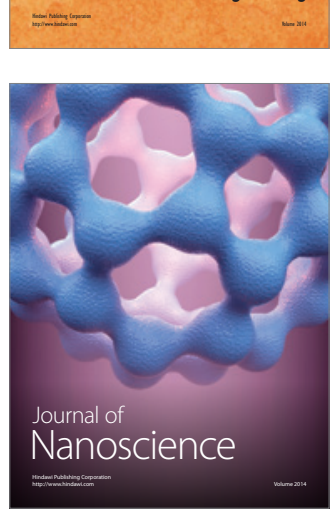
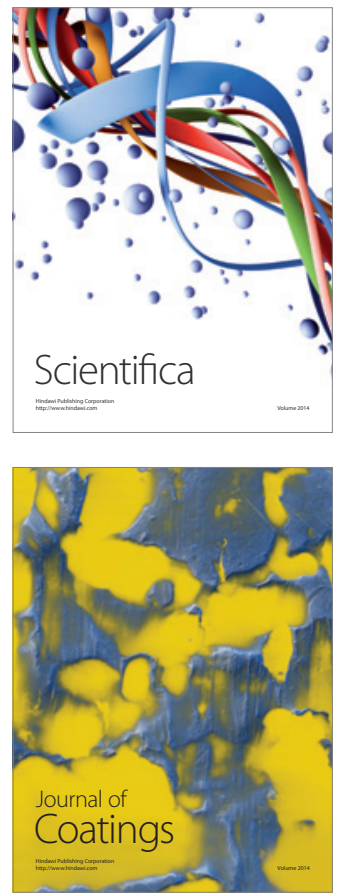
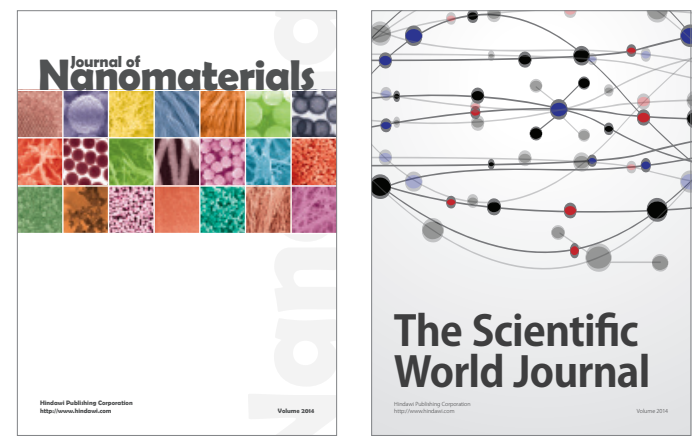

The Scientific World Journal
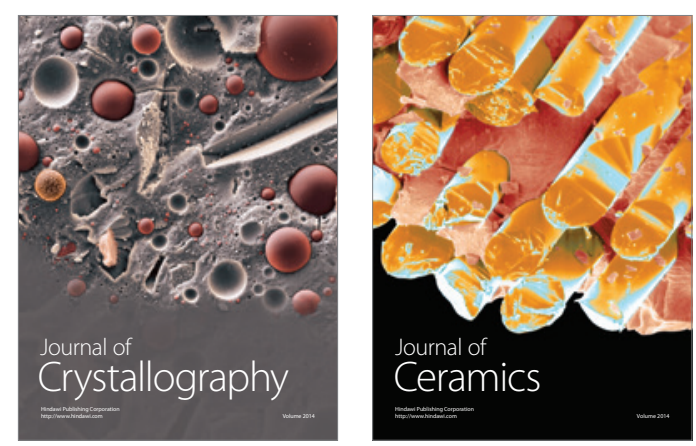
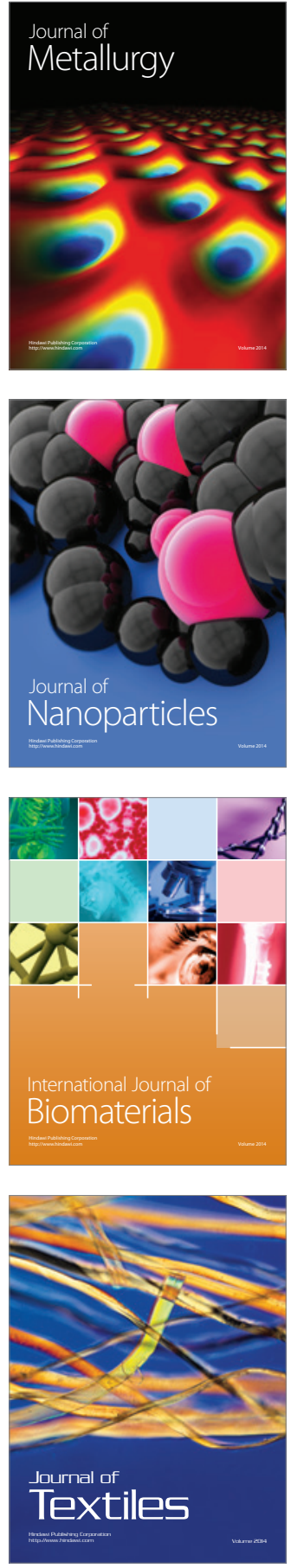